\title{
An Original Target Genetic Panel to Diagnose Neurodegenerative Diseases on the Basis of Next-Generation Sequencing:
}

First Experience

DOI: $10.17691 / \mathrm{stm} 2016.8 .4 .23$

Received March 15, 2016

N.Yu. Abramycheva, PhD, Senior Researcher, Department of Neurogenetics";

E.Yu. Fedotova, MD, PhD, Senior Researcher, Department of Neurogenetics ${ }^{1 ;}$

S.A. Klyushnikov, MD, PhD, Leading Researcher, Department of Neurogenetics ${ }^{1}$;

V.V. Ustinova, Researcher2;

V.E. Kunetsky, Master of Science ${ }^{3}$;

M.S. Stepanova, PhD, Researcher, Department of Neurogenetics';

S.L. Timerbaeva, MD, DSc, Head of the Department of Neurogenetics';

Ya.I. Alekseev, Head of the Laboratory of Genetically Modified Organisms Analysis4;

S.N. Illarioshkin, MD, DSc, Professor, Corresponding Member of the Russian Academy of Sciences,

Deputy Director for Science, Head of the Brain Research Department ${ }^{1}$

${ }^{1}$ Research Centre of Neurology, 80 Volokolamskoye Shosse, Moscow, 125367, Russian Federation;

${ }^{2}$ CJSC "Syntol", 42 Timirayzevskaya St., Moscow, 127550, Russian Federation;

${ }^{3}$ Lomonosov Institute of Fine Chemical Technologies, 78 Vernadsky Avenue, Moscow, 119454,

Russian Federation;

${ }^{4}$ All-Russia Research Institute of Agricultural Biotechnologies, 42 Timirayzevskaya St., Moscow, 127550,

Russian Federation

The aim of the study was to assess the efficacy of a diagnostic panel based on next-generation sequencing (NGS) and developed by our team, to diagnose a wide range of socially significant hereditary degenerative diseases of the brain.

Materials and Methods. Using the diagnostic target NGS panel (powered by Illumina MiSeq, USA), designed to sequence the encoding area of 300 genes related to neurodegenerative diseases manifesting with movement and cognitive disorders, we performed a mutation screening of the DNA of 32 patients with an otherwise obscure diagnosis.

Results. The application of the original genetic panel revealed a number of rare hereditary neurodegenerative pathologies with mutations in genes for spinocerebellar ataxias and paraplegias, parkinsonism, dystonias, and neurometabolic diseases, identified by NGS and confirmed by direct sequencing. In 11 patients, 12 mutations were found in 10 different genes, causing the development of three autosomal recessive diseases (genes DDHD1, NPC1 and RARS) and eight diseases associated with autosomal dominant inheritance (genes SPAST, SPTBN2, GRN, GCH1, LRRK2, NOTCH3 and AGER).

Conclusion. Panel screening of uncertain cases of neurodegenerative diseases using this bespoke target model enabled us to reveal and subsequently confirm mutations in various genes for more than a quarter of the examined patients.

Key words: next generation sequencing; target panel sequencing; neurodegenerative diseases; DNA diagnostics; gene mutation.

Introduction. Increased life expectancy and the resulting aging demographics of the population leads to an increased prevalence of degenerative diseases of the brain [1-3]. Searching for a solution to the problems caused by these pathological forms is therefore particularly topical due to the progressive course of degenerative diseases, the severity of their clinical manifestations, and the serious physical, mental and social maladjustment that can occur in patients. Genetic factors [4] in the development of neurodegenerative diseases play a significant role in early diagnosis and treatment $[5,6]$. However, DNA testing in neurodegenerative diseases presents many difficulties because of their explicit heterogeneity and thus the need for intensive searching for mutations in dozens of genes $[4,7,8]$. In this situation traditional mutation screening, based on consecutive "searching" for a plurality of coding sequences, is too time consuming and unreasonably expensive. Furthermore, for hereditary neurodegenerations, explicit inter- and intra-familial phenotypical polymorphism is typical, it being manifested by various neurological syndromes within one nosological form among members of the same family [9-12].

The development of next generation sequencing (NGS) technology in 2010-2015 was a new step in the

For contacts: Natalia Y. Abramycheva, e-mail: nataabr@rambler.ru 
molecular identification of neurodegenerative diseases. NGS technology, based on the parallel sequencing in specific microreactors of a large number of comparatively short genome sections and subsequent bioinformative complex analysis, allows us "to read" from several hundred thousand to billions (!) of base pairs in a single operating cycle [13-16].

There are three main strategies of NGS application: genome-wide sequencing, whole-exome sequencing and panel sequencing [17-18].

Genome-wide sequencing involves the identification of all the nucleotide sequences in both the coding and noncoding areas. Its obvious advantage is the possibility of identifying mutations in the regulatory and auxiliary gene regions, which generally fall outside the view of specialists in DNA diagnostics [18-20]. But genome-wide analysis is the most expensive and complicated type of NGS.

Whole-exome sequencing is the determination of the nucleotide composition of the exome, i.e. the totality of the protein-coding genome sequences. Such sequencing is, today, the principal instrument for high throughput mutation screening of genes for rare diseases and the identification of new variants of genetic markers of different nosologies. However, the high cost and considerable problems connected with processing of the obtained data prevent the implementation of genomewide and whole-exome sequencing in daily clinical diagnostics [21-23].

Panel sequencing is a target genome investigation within the loci of interest associated with specific phenotypes. The panels for NGS analysis can include from 15-20 to several hundreds of genes, the analysis of which is easier after target enrichment. In recent years the number of commercially available NGS panels in neurology has considerably increased, allowing a significant simplification of the diagnostic algorithms compared to the traditional investigation of selected, individual candidate genes [24, 25].

Our team has previously studied hereditary neurodegenerative diseases characterized by the development of motor impairments (parkinsonism, dystonia, ataxia, tremor) and cognitive impairments [26-28].

The aim of the study was to assess the effectiveness of an original diagnostic panel based on next generation genome technology for the diagnosis of a wide range of neurodegenerative diseases with motor and cognitive impairments.

Materials and Methods. In 2015-2016 the Research Center of Neurology, in cooperation with the company "Syntol", developed an original diagnostic target NGS panel (Illumina MiSeq platform, USA) for the early diagnosis and prevention of neurodegenerative diseases. The panel is aimed at sequencing the coding area of 300 genes that are particularly significant in neurodegenerative diseases manifesting in motor and cognitive impairments. These include the following: spinocerebellar ataxia (136 genes); spastic paraplegia (43 genes); dementia (23 genes); leukodystrophy and leukoencephalopathy (22 genes); primary parkinsonism (20 genes); amyotrophic lateral sclerosis (20 genes); primary dystonia (16 genes); neurodegeneration with brain iron accumulation (6 genes); primary chorea (6 genes); essential tremor (4 genes); Fahr disease (3 genes); hepatolenticular degeneration (1 gene).

The first stage. Mutation screening with the above target genetic panel was performed in the Research Center of Neurology. The test group involved 32 patients with different neurodegenerative pathologies, where other (traditional) molecular-genetic methods had not identified the mutations involved.

The study was performed in accordance with the Helsinki declaration (accepted June 1964 (Helsinki, Finland) and reviewed in October 2000 (Edinburgh, Scotland)) and approved by the Ethical Committee of the Research Center of Neurology. All the patients gave written, informed consent for the scientific analysis of their findings.

The following aspects were taken into account for patients' inclusion: phenotype with extremely explicit genetic heterogeneity (for example, ataxia of degenerative origin); a phenotype which did not correspond to any typical clinical forms of neurodegenerative pathology (i.e. having certain features or combining several syndromes); a phenotype that implied specific genes, which are either rather long for routine diagnostics or rare (i.e. with undeveloped molecular-genetic research protocols); preference was given to family cases where further comparative analysis of the proband and his/her healthy/ ill relatives was possible.

Samples of genomic DNA were extracted from leucocytes of peripheral blood using a Wizard Genomic DNA Purification Kit (Promega, USA).

Ahead of the study, standard DNA tests had been used to exclude patients with possible genetic disorders that could lead to the corresponding phenotype. In the case of ataxic and choreal syndromes, fragment analysis was used to exclude the presence of "dynamic" mutations (presence of the expansion of microsatellite repeats in the genes: ATXN1, ATXN2, ATXN3, CACNL1A4, ATXN7, FXN, HTT, DRPLA, JPH3 and TBP) [29, 30]. For the patients with dementia, we excluded the presence of the expansion of hexanucleotide repeats in the C9orf72 gene [31]. Molecular-genetic tests based on the realtime polymerase chain reaction method excluded CAG deletion in the TORIA gene in dystonia [32], major mutations N370S and L444P in gene GBA and G2019S in gene $L R R K 2$ in Parkinson's disease [33], etc. Mutation screening of the genes PINK1, SNCA, ATP13A2, LRRK2, $P A R K 2$ and PARK7 was performed using the multiplex ligase reaction with amplification technique to identify the presence of large deletions and duplications in different variants of parkinsonism.

The second stage. Target sequencing based on NGS was performed at the Center for the Collective Use of Biotechnology Equipment of the Russian Research Institute of Agricultural Technologies. Fragmentation of 
the DNA samples, into segments with an average size of 180-220 bp, was performed using ultrasound exposure with an S220 System (Covaris, USA), in $52.5 \mu$ l volumes of TE-buffer (10 mM Tris-HCl, pH 8.0, 1 mM EDTA). The libraries were prepared with the KAPA Library Preparation Kit (Roche, Switzerland). DNA library enrichment was performed in accordance with SeqCap EZ Library SR technology with specific biotinylated oligonucleotide probes complementary with the sequences of the coding gene areas included in our panel. Sequencing of the obtained DNA libraries was performed over 150 cycles, on an Illumina MiSeq platform (USA), using a sequencing reagent kit $\left(\mathrm{MiSeq}^{\circledR}\right.$ Reagent Kit v3). Sequences of adapters, nucleotides with a quality lower than q20, and $\mathrm{N}$-nucleotides were removed from the resulting readings with Trimmomatic 0.33 (http://www.usadellab. org/cms/?page=trimmomatic). The sequences were mapped on the human genome (GRCh38) using Bowtie2 software [34]; on average $98 \%$ of readings were mapped successfully. The search for nucleotide substitutions was performed using GATK 3.1 (https://software. broadinstitute.org/gatk/), and for their annotation the wANNOVAR online resource [35] was used. To evaluate the pathogenicity of the identified variants we used the following databases: Human Gene Mutation Database (http://www.hgmd.cf.ac.uk), dbSNP (http://www.ncbi.nlm. nih.gov/snp), OMIM (http://www.omim.org/) and ClinVar (http://www.ncbi.nlm.nih.gov/clinvar/).

All the obtained variants of nucleotide substitutions were confirmed by capillary sequencing on the NANOFOR 05 (Russia) genetic analyzer. The closest relatives of the probands, if available, were examined in respect of the identified mutations confirmed by standard Sanger sequencing.

Results and Discussion. We revealed 12 mutations in 10 different genes in 11 patients, causing the development of three autosomal recessive diseases (DDHD1, NPC1 and RARS genes), together with eight diseases connected with autosomal dominant inheritance (SPAST, SPTBN2, GRN, GCH1, LRRK2, NOTCH3 and $A G E R$ ) (See the Table). The effectiveness of the panel from the point of view of mutation identification was $34 \%$.

Case 1. Member of a large family, four generations of which have an autosomal dominant form of hereditary spastic paraplegia (Strümpell disease). Two male cousins were examined at the ages of 52 and 59 and shown to have the missense mutation $T 541 \mathrm{~N}$ in the $15^{\text {th }}$ exon of the SPAST gene on chromosome 2p24-p21, which corresponds to the molecular diagnosis of type 4 (SPG4) hereditary spastic paraplegia.

Case 2. A four-year old child with delayed psychomotor development and lower spastic paraplegia syndrome, having a mutation in a homozygous state in the form of the insertion of six nucleotides 5361949453619495insCGCCGC in the DDHD1 gene on chromosome 14q22.1. This mutation causes the insertion of two amino acids into the corresponding protein: Gly112_Ser113insGlyGly. According to the bioinformation sources, this mutation is pathological and associated with the development of type 28 (SPG28) autosomal recessive form of spastic paraplegia.

Case 3. A 22-year old female patient who has suffered from gradually progressing ataxia, oculomotor impairments (vertical gaze paresis), cognitive decline, dystonia, and splenomegaly since she was ten. Such a combination of neurological and somatic pathology suggests a disease resulting from a group of hereditary metabolic disorders. As the result of the NGS analysis, we identified a pathogenic missense mutation G922R in

\section{Mutations revealed with NGS technology and molecular diagnoses corresponding to these mutations}

\begin{tabular}{clccclcc}
\hline $\begin{array}{c}\text { Case } \\
\text { No. }\end{array}$ & \multicolumn{1}{c}{ Clinical picture } & Gene & Mutation & Zygosity & Diagnosis & $\begin{array}{c}\text { Inheritance } \\
\text { type }\end{array}$ \\
\hline 1 & Spastic paraparesis of the lower limbs & SPAST & T541N & Het & Hereditary spastic paraplegia, type 4 (SPG4) & AD \\
\hline 2 & Spastic paraparesis of the lower limbs & DDHD1 & G112_S113 insGG & Hom & Hereditary spastic paraplegia, type 28 (SPG28) & AR \\
\hline 3 & Ataxia, dystonia, cognitive impairment & NPC1 & Q119X & Het & Nieman-Pick disease, type C & AR \\
\hline 4 & Cerebellar ataxia & SPTBN2 & R1880H & Het & Spinocerebellar ataxia, type 5 (SCA5) & AD \\
\hline 5 & Dementia & GRN & N33Q & Het & Frontotemporal dementia (GRN-associated) & AD \\
\hline 6 & Dystonia & GCH1 & S139fs & Het & Dopa-responsive dystonia (DYT5 form) & AD \\
\hline 7 & Parkinsonism, responsive to levodopa & LRRK2 & R1398H & Het & Parkinson's disease (PARK8 form) & AD \\
\hline 8 & Parkinsonism, responsive to levodopa & LRRK2 & M1646T & Het & Parkinson's disease (PARK8 form) & AD \\
\hline 9 & Leukoencephalopathy & NOTCH3 & H1133Q & Het & CADASIL & AD \\
\hline 10 & Aphasia-dementia & AGER & C38W & Het & Alzheimer's disease (AGER -associated) & AD \\
\hline 11 & Mild tetraparesis of the limbs & RARS & F397Y & Hom & One of the rare forms of leukodystrophy & AR \\
\hline
\end{tabular}

Notes. CADASIL: cerebral autosomal dominant arteriopathy with subcortical infarcts and leukoencephalopathy. Het: heterozygous mutation, Hom: homozygous mutation, AD: autosomal dominant, AR: autosomal recessive. 
the $20^{\text {th }}$ exon, and a new nonsense mutation Q119X in the $4^{\text {th }}$ exon of the NPC1 gene, both being in a compoundheterozygous state which resulted in a severe autosomal recessive disease - Nieman-Pick disease, type $C$.

Case 10. A 51-year old patient, who has a four-year medical history of gradually developing aphasic and cognitive impairments, also has a pathogenic mutation in a new AGER gene associated with Alzheimer's disease.

It is important to note that in modern laboratory practice, NGS and traditional methods of mutation screening are complementary. So, for example, with NGS it is impossible to determine such a neurologically frequent type of mutation as the expansion of trinucleotide repeats [30, 31], and all nucleotide variants revealed by NGS are to be strictly confirmed with classical sequencing. It is evident that the future of moleculargenetic diagnostics is in the combination of these methods and technologies.

Conclusion. Target genetic panels based on NGS are indispensable and economically justified in diagnoses of those hereditary diseases of the nervous system that are characterized by genetic heterogeneity and phenotypic polymorphism.

The target genetic panel that has been developed has shown its effectiveness during the screening of otherwise obscure cases of neurodegenerative diseases manifested by motor and cognitive impairments, enabling us to identify mutations in different genes in more than a third of all the cases studied.

Study Funding. The work was supported by the Ministry of Education and Science of the Russian Federation under the Federal Target Program "Investigations and Developments in Priority Spheres of the Development of the Scientific-Technological Complex in Russia for 2014-2020", grant agreement No.14.607.21.0094, dated 27 November 2014 (unique identification number of the project RFMEFI60714X0094).

Conflicts of Interest. The authors declare no conflicts of interest.

\section{References}

1. Wimo A., Winblad B., Jönsson L. An estimate of the total worldwide societal costs of dementia in 2005. Alzheimers Dement 2007; 3(2): 81-91, https://doi.org/10.1016/j. jalz.2007.02.001.

2. Peine A., Faulkner A., Jæger B., Moors E. Science, technology and the "grand challenge" of ageing understanding the socio-material constitution of later life. Technological Forecasting and Social Change 2015; 93: 1-9, https://doi.org/10.1016/j.techfore.2014.11.010.

3. Apokin A., Belousov D., Salnikov V., Frolov I. Long-term Socioeconomic challenges for Russia and demand for new technology. Foresight and STI Governance 2015; 9(4): 6-17.

4. Illarioshkin S.N. DNK-diagnostika $i$ medikogeneticheskoe konsul'tirovanie [DNA diagnostics and genetic consultation]. Moscow: Meditsinskoe informatsionnoe agentstvo; 2004.
5. Karpova E.A., Ivanova-Smolenskaya I.A., Illarioshkin S.N., Markova E.D., Chernikova L.A., Timerbaeva S.L. Dynamics of main symptoms of Parkinson disease on Pronoran therapy. Nevrologicheskii zhurnal 2003; 8(2): 49-52.

6. Illarioshkin S.N. Parkinsonism therapy: possibilities and prospects. Nevrologiya i revmatologiya. Prilozhenie k zhurnalu Consilium Medicum 2009; 1: 35-40.

7. Illarioshkin S.N., Markova E.D., Slominsky P.A., Miklina N.I., Popova S.N., Limborska S.A., Tsuji S., Ivanova-Smolenskaya I.A. The GTP cyclohydrolase I gene in Russian families with dopa-responsive dystonia. Archives of Neurology 1998; 55(6): 789-792, https://doi.org/10.1001/ archneur.55.6.789.

8. Illarioshkin S.N., Rakhmonov R.A., IvanovaSmolenskaya I.A., Brice A., Markova E.D., Miklina N., Kliushnikov S.A., Limborskaia S.A. Molecular genetic analysis of essential tremor. Genetics 2002; 38(12): 1447-1451.

9. Wilkie G.S., Schirmer E.C. Guilt by association. The nuclear envelope proteome and disease. Mol Cell Proteomics 2006; 5(10): 1865-1875, https://doi.org/10.1074/mcp.r600003mcp200.

10. Schneider S.A., Schneider U.H., Klein C. Genetic testing for neurologic disorders. Semin Neurol 2011; 31(5): 542-552, https://doi.org/10.1055/s-0031-1299792.

11. Hersheson J., Haworth A., Houlden H. The inherited ataxias: genetic heterogeneity, mutation databases, and future directions in research and clinical diagnostics. Hum Mutat 2012; 33(9): 1324-1332, https://doi.org/10.1002/humu.22132.

12. Klebe S., Stevanin G., Depienne C. Clinical and genetic heterogeneity in hereditary spastic paraplegias: from SPG1 to SPG72 and still counting. Rev Neurol 2015; 171(6-7): 505530, https://doi.org/10.1016/j.neurol.2015.02.017.

13. Metzker M.L. Sequencing technologies - the next generation. Nat Rev Genet 2010; 10(1): 31-46, https://doi. org/10.1038/nrg2626.

14. Erdmann J. Next generation technology edges genome sequencing toward the clinic. Chem Biol 2011; 18(12): 15131514, https://doi.org/10.1016/j.chembiol.2011.12.006.

15. Pareek C.S., Smoczynski R., Tretyn A. Sequencing technologies and genome sequencing. J Appl Genet 2011; 52(4): 413-435, https://doi.org/10.1007/s13353-011-0057-x.

16. Xue Y., Ankala A., Wilcox W.R., Hegde M.R. Solving the molecular diagnostic testing conundrum for Mendelian disorders in the era of next-generation sequencing: singlegene, gene panel, or exome/genome sequencing. Genet Med 2015; 17(6): 444-451, https://doi.org/10.1038/gim.2014.122.

17. Rebrikov D.V., Korostin D.O., Shubina E.S., Il'inskiy V.V. NGS: vysokoproizvoditel'noe sekvenirovanie [NGS: highefficiency sequencing]. Moscow: BINOM; 2014.

18. Warman Chardon J., Beaulieu C., Hartley T., Boycott K.M., Dyment D.A. Axons to exons: the molecular diagnosis of rare neurological diseases by next-generation sequencing. Curr Neurol Neurosci Rep 2015; 15(9): 584-592, https://doi.org/10.1007/s11910-015-0584-7.

19. Boycott K., Hartley T., Adam S., Bernier F., Chong K., Fernandez B.A., Friedman J.M., Geraghty M.T., Hume S., Knoppers B.M., Laberge A.M., Majewski J., Mendoza-Londono R., Meyn M.S., Michaud J.L., Nelson T.N., Richer J., Sadikovic B., Skidmore D.L., Stockley T., Taylor S., van Karnebeek C., Zawati M.H., Lauzon J., Armour C.M. The clinical application of genome-wide sequencing for monogenic diseases in Canada: position statement of the Canada College 
of Medical Geneticists. J Med Genet 2015; 52: 431-437, https://doi.org/10.1136/jmedgenet-2015-103144.

20. Foo J.-N., Liu J.-J., Tan E.-K. Whole-genome and whole-exome sequencing in neurological diseases. Nat Rev Neurol 2012; 8(9): 508-517, https://doi.org/10.1038/ nrneurol.2012.148.

21. Green R.C., Berg J.S., Grody W.W., Kalia S.S., Korf B.R., Martin C.L., McGuire A.L., Nussbaum R.L., O'Daniel J.M., Ormond K.E., Rehm H.L., Watson M.S., Williams M.S., Biesecker L.G.; American College of Medical Genetics and Genomics. ACMG recommendations for reporting of incidental findings in clinical exome and genome sequencing. Genet Med 2013; 15(7): 565-574, https://doi. org/10.1038/gim.2013.73.

22. Fogel B.L., Lee H., Deignan J.L., Strom S.P., Kantarci S., Wang X., Quintero-Rivera F., Vilain E., Grody W.W., Perlman S., Geschwind D.H., Nelson S.F. Exome sequencing in the clinical diagnosis of sporadic or familial cerebellar ataxia. JAMA Neurol 2014; 71(10): 1237-1246, https://doi.org/10.1001/jamaneurol.2014.1944.

23. Farwell K.D., Shahmirzadi L., El-Khechen D., Powis Z., Chao E.C., Tippin D.B., Baxter R.M., Zeng W., Mroske C., Parra M.C., Gandomi S.K., Lu I., Li X., Lu H., Lu H.M., Salvador D., Ruble D., Lao M., Fischbach S., Wen J., Lee S., Elliott A., Dunlop C.L., Tang S. Enhanced utility of familycentered diagnostic exome sequencing with inheritance modelbased analysis: results from 500 unselected families with undiagnosed genetic conditions. Genet Med 2015; 17(7): 578586, https://doi.org/10.1038/gim.2014.154.

24. de Koning T.J., Jongbloed J.D.H., Sikkema-Raddatz B., Sinke R.J. Targeted next-generation sequencing panels for monogenetic disorders in clinical diagnostics: the opportunities and challenges. Expert Rev Mol Diagn 2015; 15(1): 61-70, https://doi.org/10.1586/14737159.2015.976555.

25. Illarioshkin S.N., Abramycheva N.Yu., IvanovaSmolenskaya I.A. Molekulyarno-geneticheskaya diagnostika zabolevaniy nervnoy sistemy. V kn.: Nevrologiya XXI veka: diagnosticheskie, lechebnye $i$ issledovatel'skie tekhnologii. T. I. Sovremennye tekhnologii diagnostiki zabolevaniy nervnoy sistemy [Molecular genetic diagnostics of the diseases of the nervous system. In: Neurology of XXI century: diagnostic, treatment and research technologies. Volume I. Modern technologies for diagnostics of the nervous system diseases]. Pod red. Piradova M.A., Illarioshkina S.N., Tanashyan M.M. [Piradov M.A., Illarioshkin S.N., Tanashyan M.M. (editors)]. Moscow: OOO "ATMO" 2015; p. 329-362.

26. Illarioshkin S.N., Ivanova-Smolenskaya I.A., Markova E.D., Shadrina M.I., Klyushnikov S.A., Zagorovskaya T.B., Miklina N.I., Slominsky P.A., Limborska S.A. Molecular genetic analysis of hereditary neurodegenerative diseases. Russian Journal of Genetics 2004; 40(6): 663-671, https://doi.org/10.1023/b:ruge.0000033314.49573.db.
27. Abramycheva N., Stepanova M., Kalashnikova L., Zakharova M., Maximova M., Tanashyan M., Lagoda O., Fedotova E., Klyushnikov S., Konovalov R., Sakharova A., Illarioshkin S. New mutations in the Notch3 gene in patients with cerebral autosomal dominant arteriopathy with subcortical infarcts and leucoencephalopathy (CADASIL). J Neurol Sci 2015; 349(1-2): 196-201, https://doi.org/10.1016/j.jns.2015.01.018.

28. Abramycheva N.Y., Fedotova E.Y., Stepanova M.S., Timerbaeva S.L., Illarioshkin S.N. New approach to molecular and genetic screening of patients with Parkinson 's disease. Nevrologicheskii zhurnal 2016; 21(1): 13-16.

29. Illarioshkin S.N., Ivanova-Smolenskaya I.A., Markova E.D. A new mutational mechanism in man: expansion of trinucleotide repeats. Genetika 1995; 31(11): 1478-1489.

30. Platonov F.A., Illarioshkin S.N., Kononova S.K., Gogolev M.P., Ivanova-Smolenskaya I.A. Type 1 spinocerebellar ataxia in Yakutia: incidence and clinico-genetic comparisons. Meditsinskaya genetika 2004; 3(5): 242-248.

31. Gijselinck I., Van Langenhove T., Van der Zee J., Sleegers K., Philtjens S., Kleinberger G., Janssens J., Bettens K., Van Cauwenberghe C., Pereson S., Engelborghs S., Sieben A., De Jonghe P., Vandenberghe R., Santens P., De Bleecker J., Maes G., Bäumer V., Dillen L., Joris G., Cuijt I., Corsmit E., Elinck E., Van Dongen J., Vermeulen S., Van den Broeck M., Vaerenberg C., Mattheijssens M., Peeters K., Robberecht W., Cras P., Martin J.J., De Deyn P.P., Cruts M., Van Broeckhoven C. A C9orf72 promoter repeat expansion in a Flanders-Belgian cohort with disorders of the frontotemporal lobar degenerationamyotrophic lateral sclerosis spectrum: a gene identification study. Lancet Neurol 2012; 11(1): 54-65, https://doi.org/ 10.1016/s1474-4422(11)70261-7.

32. Slominsky P.A., Markova E.D., Shadrina M.I., Illarioshkin S.N., Miklina N.I., Limborska S.A., IvanovaSmolenskaya I.A. A common 3-bp deletion in the DYT1 gene in Russian families with early-onset torsion dystonia. Human Mutat 1999; 14(3): 269, https://doi.org/10.1002/(sici)10981004(1999)14:3<269::aid-humu12>3.0.co;2-9.

33. Illarioshkin S.N., Shadrina M.I., Slominsky P.A., Bespalova E.V., Zagorovskaya T.B., Bagyeva G.Kh., Markova E.D., Limborska S.A., Ivanova-Smolenskaya I.A. A common leucine-rich repeat kinase 2 gene mutation in familial and sporadic Parkinson's disease in Russia. Eur J Neurol 2007; 14(4): 413-417, https://doi.org/10.1111/j.14681331.2007.01685.x.

34. Langmead B., Salzberg S.L. Fast gapped-read alignment with Bowtie 2. Nat Methods 2012; 9(4). 357-359, https://doi.org/10.1038/nmeth.1923.

35. Yang H., Wang K. Genomic variant annotation and prioritization with ANNOVAR and WANNOVAR, Nat Protoc 2015; 10(10): 1556-1566, https:Hdol.org/10.1038/ nprot.2015.105. 